\title{
Reactive Astrocytes Overexpress TSPO and Are Detected by TSPO Positron Emission Tomography Imaging
}

\author{
Sonia Lavisse, ${ }^{1}$ Martine Guillermier, ${ }^{1 \star}$ Anne-Sophie Hérard, ${ }^{1 \star}$ Fanny Petit, ${ }^{1 \star}$ Marion Delahaye, ${ }^{1}$ Nadja Van Camp, ${ }^{1}$ \\ Lucile Ben Haim, ${ }^{1}$ Vincent Lebon, ${ }^{1}$ Philippe Remy, ${ }^{1,2}$ Frédéric Dollé, ${ }^{3}$ Thierry Delzescaux, ${ }^{1}$ Gilles Bonvento, ${ }^{1}$ \\ Philippe Hantraye, ${ }^{1}$ and Carole Escartin ${ }^{1}$ \\ ${ }^{1}$ Commissariat à l'Energie Atomique et aux Energies Alternatives (CEA), Département des Sciences du Vivant (DSV), Institut d'Imagerie Biomédicale, \\ MIRCen and CNRS, URA2210 (I2BM), 92260 Fontenay-aux-Roses, France, ${ }^{2}$ Neurology Department, Henri Mondor University Hospital, 94000 Créteil, \\ France, and ${ }^{3} \mathrm{CEA}$, DSV, I2BM, Service Hospitalier Frédéric Joliot, 91400 Orsay, France
}

Astrocytes and microglia become reactive under most brain pathological conditions, making this neuroinflammation process a surrogate marker of neuronal dysfunction. Neuroinflammation is associated with increased levels of translocator protein $18 \mathrm{kDa}$ (TSPO) and binding sites for TSPO ligands. Positron emission tomography (PET) imaging of TSPO is thus commonly used to monitor neuroinflammation in preclinical and clinical studies. It is widely considered that TSPO PET signal reveals reactive microglia, although a few studies suggested a potential contribution of reactive astrocytes. Because astrocytes and microglia play very different roles, it is crucial to determine whether reactive astrocytes can also overexpress TSPO and yield to a detectable TSPO PET signal in vivo. We used a model of selective astrocyte activation through lentiviral gene transfer of the cytokine ciliary neurotrophic factor (CNTF) into the rat striatum, in the absence of neurodegeneration. CNTF induced an extensive activation of astrocytes, which overexpressed GFAP and become hypertrophic, whereas microglia displayed minimal increasein reactivemarkers. Two TSPOradioligands, $\left[{ }^{18} \mathrm{~F}\right] \mathrm{DPA}-714\left[\mathrm{~N}, \mathrm{~N}\right.$-diethyl-2-(2-(4- $\left(2-\left[{ }^{18} \mathrm{~F}\right]\right.$ fluoroethoxy)phenyl)-5,7-dimethylpyrazolo[1, 5-a]pyrimidin-3-yl)acetamide] and [ $\left.{ }^{11} \mathrm{C}\right] \mathrm{SSR} 180575$ (7-chloro- $N, N$-dimethyl-5-[ $\left.{ }^{11} \mathrm{C}\right]$ methyl-4-oxo-3-phenyl-3,5-dihydro-4H-pyridazino[4,5$b$ ]indole-1-acetamide), showed a significant binding in thelenti-CNTF-injected striatum that was saturated and displaced by PK11195 [ $N$-methyl$\mathrm{N}$-(1-methylpropyl)-1-(2-chlorophenyl)-isoquinoline-3-carboxamide]. The volume of radioligand binding matched the GFAP immunopositive volume. TSPO mRNA levels were significantly increased, and TSPO protein was overexpressed by CNTF-activated astrocytes. We show that reactive astrocytes overexpress TSP0, yielding to a significant and selective binding of TSPO radioligands. Therefore, caution must be used when interpreting TSPO PET imaging in animals or patients because reactive astrocytes can contribute to the signal in addition to reactive microglia.

\section{Introduction}

In response to multiple abnormal situations in the brain, astrocytes and microglia become reactive. This neuroinflammation process involves stereotypic morphological changes and multiple functional alterations (Hanisch and Kettenmann, 2007; Escartin

\footnotetext{
Received March 27, 2012; revised May 22, 2012; accepted June 12, 2012.

Author contributions: S.L., P.H., and C.E. designed research; S.L., M.G., F.P., M.D., N.V.C., L.B.H., G.B., and C.E. performed research; V.L., P.R., F.D., and T.D. contributed unpublished reagents/analytic tools; S.L., M.G., A.-S.H., F.P., and C.E. analyzed data; S.L. and C.E. wrote the paper.

${ }^{*}$ M.G., A.-S.H., and F.P. contributed equally to this study.

This work was supported by European Specific Targeted Research Projects Program STEMS Grant LSHB-CT-2006037328 (P.H.), National Agency for Research Grant ANR-2010-JCIC-1402-1 (C.E.), Atomic Energy and Alternative Energies Commission, and National Center of Scientific Research. We are grateful to Marion Chaigneau, Diane Houitte, and Charlène Joséphine for expert technical assistance with animal handling, Yoan Fontyn and Nicolas Souedet for reconstruction of PET data, Dr. Elsa Diguet for help with animal transfer for $\left[{ }^{11} \mathrm{C}\right]$ SSR180575 imaging sessions and quinolinate injections, Dr. Nicole Déglon, Noëlle Dufour, and Gwennaelle Auregan for lentiviral vector production, and Stéphane Demphel, Stéphane Le Helleix, and Tony Catarina for radioligand synthesis. We also thank Dr. Emmanuel Brouillet for stimulating discussions on the project, Dr. Caroline Jan for her assistance to preliminary experiments, and Drs. Frank Marguet, Frédéric Puech, and Thomas Rooney (Sanofi, Chilly-Mazarin, France) for scientific discussions on the TSPO $18 \mathrm{kDa}$ target and data sharing. Finally, we are extremely grateful to Dr. Makoto Higuchi (National Institute of Radiological Sciences, Chiba, Japan) for sharing his TSPO antibody and for his careful reading of this manuscript.

Correspondence should be addressed to Carole Escartin, CEA CNRS URA2210, MIRCen 18, route du Panorama, 92260 Fontenay-aux-Roses, France. E-mail: carole.escartin@cea.fr.

DOI:10.1523/JNEUROSCI.1487-12.2012

Copyright $\odot 2012$ the authors $\quad 0270-6474 / 12 / 3210809-10 \$ 15.00 / 0$
}

and Bonvento, 2008). Because glial cell activation not only mirrors neuronal dysfunction but can also directly influence disease progression, considerable efforts have been made to develop non-invasive techniques to monitor these cells in vivo. Such techniques would enable evaluation of disease progression and therapeutic efficacy in animal models and patients suffering from multiple neurodegenerative diseases.

Positron emission tomography (PET) imaging of the translocator protein $18 \mathrm{kDa}$ (TSPO) has been proposed as a potent strategy to monitor neuroinflammation in animals and humans (Chen and Guilarte, 2008). TSPO is expressed by glial cells and is upregulated under neuroinflammatory conditions (Rupprecht et al., 2010), serving as a biomarker for PET imaging ofneuroinflammation usingTSPOradioligands. $\left[{ }^{11} \mathrm{C}\right]$ (R)-PK11195 [N-methyl-N-(1-methylpropyl)-1-(2-chlorophenyl)-isoquinoline-3-carboxamide], was one of the first TSPO-selective radioligands to be developed and has been used extensively in animals and patients for two decades (Venneti et al., 2006; Chauveau et al., 2008). Multiple other TSPO radioligands have since been generated, including $\left[{ }^{18} \mathrm{~F}\right] \mathrm{DPA}-714$ [N,N-diethyl-2-(2(4-(2-[ $\left.{ }^{18} \mathrm{~F}\right]$ fluoroethoxy)phenyl)-5,7-dimethylpyrazolo $[1,5-\mathrm{a}]$ pyrimidin-3-yl)acetamide] (James et al., 2008) and [ $\left.{ }^{11} \mathrm{C}\right]$ SSR 180575 (7-chloro- $N$, N-dimethyl-5- $\left[{ }^{11} \mathrm{C}\right]$ methyl-4-oxo-3-phenyl-3,5- 
dihydro- $4 H$-pyridazino[4,5- $b$ indole-1-acetamide) (Thominiaux et al., 2010).

Despite the multiplicity of TSPO radioligands available, it is still unclear whether TSPO PET signal arises from reactive astrocytes or microglia. It is generally admitted that reactive microglia are responsible for the signal observed with TSPO radioligands (Venneti et al., 2006; Chauveau et al., 2008, 2009). However, an original study reported that astrocytes overexpress TSPO (Kuhlmann and Guilarte, 2000), and others have suggested their potential contribution to the TSPO PET signal (Rojas et al., 2007; Ji et al., 2008). The major limitation of PET studies exploring TSPO expression is the animal model used (intracerebral injection of neurotoxins, ischemia, transgenic mice) or the clinical disease considered. Most of them display activation of both astrocytes and microglia, limiting the interpretation of PET data. Additional confounding factors include neuronal degeneration, blood-brain barrier disruption, and peripheral immune cell recruitment. Determining the relative contribution of each cell type to the PET signal is therefore difficult, and it remains to be established whether reactive astrocytes give rise to a detectable TSPO PET signal, in the absence of reactive microglia and neurodegeneration. It is also crucial to assess whether TSPO PET imaging allows discrimination of reactive microglia from reactive astrocytes, because these two cell types play very distinct functions and may influence disease progression in opposite ways.

For this purpose, we have developed a model of selective activation of astrocytes through lentiviral gene transfer of the cytokine ciliary neurotrophic factor (CNTF) in the rat brain, in the absence of detectable microglia reactivity, neuronal degeneration, or any additional pathological process (Escartin et al., 2006, 2007; Beurrier et al., 2010). We used this unique model to assess whether reactive astrocytes can overexpress TSPO and generate a detectable TSPO PET signal using two recently developed and onsite available TSPO radioligands, $\left[{ }^{18} \mathrm{~F}\right] \mathrm{DPA}-714$ and $\left[{ }^{11} \mathrm{C}\right] \mathrm{SSR} 180575$.

\section{Materials and Methods}

Reagents and animals. All reagents came from Sigma unless specified otherwise. All animal experimental procedures were performed in strict accordance with the French regulation (Code Rural R214/87 to R214/ 130 ) and the recommendations of the European Economic Community (86/609/EEC) for care and use of laboratory animals, and conformed to the ethical guidelines of the French National Charter on the ethics of animal experimentation. The animal facility is accredited by the French authorities (Veterinary Inspectors) under number B92-032-02.

Lentivirus injection. We used self-inactivated lentiviruses that encode either the human CNTF gene ("lenti-CNTF") with the export sequence of Ig or the $\beta$-galactosidase gene ("lenti-LacZ") under the control of the mouse phosphoglycerate kinase 1 promoter, as described previously (Escartin et al., 2006).

Male Sprague Dawley rats (2-month-old) were anesthetized with a mixture of ketamine $(75 \mathrm{mg} / \mathrm{kg})$ and xylazine $(10 \mathrm{mg} / \mathrm{kg})$. Suspensions of lentiviral vector $(2 \mu \mathrm{l}, 100 \mathrm{ng} \mathrm{p} 24 / \mu \mathrm{l}$, diluted in PBS with $1 \% \mathrm{BSA})$ were injected into the striatum at a rate of $0.2 \mu \mathrm{l} / \mathrm{min}$, using a 34-gauge blunt-tip needle linked to a Hamilton syringe by a polyethylene catheter. Rats were injected with lenti-LacZ and lenti-CNTF in the left and right striatum, respectively. The stereotaxic coordinates, from bregma, were as follows: anteroposterior, $+0.5 \mathrm{~mm}$; lateral, $\pm 3 \mathrm{~mm}$; and ventral, $-4.5 \mathrm{~mm}$ from the dura, with tooth bar set at $-3.3 \mathrm{~mm}$. At the end of the injection, the needle was left in place for 5 min before being slowly removed. The skin was sutured, and rats were allowed to recover for at least 2 months before being scanned. Rats were analyzed between 2 and 6 months after injection, because CNTF effects were shown to be stable for at least 6 months (Escartin et al., 2006).

To serve as a positive control for neuroinflammation involving both reactive astrocytes and microglia (Ryu et al., 2005), we injected nine rats with $80 \mathrm{nmol}$ of quinolinate (QA) in the striatum, as described previously (Beurrier et al., 2010). After 2 weeks, eight rats were perfused, and one rat had its brain frozen, as described below (see Immunohistology).

Radioligand synthesis. Ready-to-inject, $>99 \%$ radiochemically pure $\left[{ }^{18} \mathrm{~F}\right] \mathrm{DPA}-714$ was prepared from cyclotron-produced $\left[{ }^{18} \mathrm{~F}\right]$ fluoride (Cyclone-18/9 cyclotron; IBA) on the basis of already published standard conditions (Damont et al., 2008; James et al., 2008) using a TRACERLab FX-FN synthesizer (GEMS). Radiolabeling of DPA-714 with fluorine-18 uses a tosyloxy-for-fluorine nucleophilic aliphatic substitution (one-step process), and its preparation includes the following five stages: (1) dilution of the no-carrier-added, dried (activated) K $\left[{ }^{18} \mathrm{~F}\right] \mathrm{F}$-Kryptofix 222 complex (prepared from $\left[{ }^{18} \mathrm{~F}\right]$ fluoride, potassium carbonate, and Kryptofix 222) with $700 \mu \mathrm{l}$ of dimethylsulfoxide containing 3.5-4.5 mg of the tosyloxy precursor for labeling [N,N-diethyl-2-(2-(4-(2-toluene sulfonyloxyethoxy)phenyl)-5,7-dimethylpyrazolo[1,5-a]pyrimidin-3yl)acetamide]; (2) heating the reaction mixture at $160^{\circ} \mathrm{C}$ for $5 \mathrm{~min}$; (3) dilution of the reaction mixture with the HPLC mobile phase and prepurification on a SepPak Alumina N cartridge; (4) HPLC purification on a semi-preparative Waters $\mathrm{X}$-Terra $\mathrm{C}-18$ column (eluent: $0.1 \mathrm{M}$ aqueous ammonium acetate, $\mathrm{pH}$ 10/acetonitrile, 60:40 v/v); and (5) SepPak Plus C-18 cartridge-based removal of the HPLC solvents. $\left[{ }^{18} \mathrm{~F}\right] \mathrm{DPA}-714$, as an ethanolic (15\%) physiological saline solution (6.7 to $8.5 \mathrm{GBq}$ batches, $10 \mathrm{ml}$-volume), is routinely obtained within $50-55 \mathrm{~min}$ starting from 35 GBq of $\left[{ }^{18} \mathrm{~F}\right]$ fluoride $(19-24 \%$ non-decay-corrected overall isolated yields) with specific radioactivities ranging from 74 to $222 \mathrm{GBq} / \mu \mathrm{mol}$.

Ready-to-inject, $>99 \%$ radiochemically pure $\left[{ }^{11} \mathrm{C}\right] \mathrm{SSR} 180575$ was prepared from cyclotron-produced $\left[{ }^{11} \mathrm{C}\right]$ carbon dioxide (Cyclone-18/9 cyclotron; IBA) using a TRACERLab FX-C synthesizer (GEMS) as described previously (Thominiaux et al., 2010). SSR180575 was labeled with carbon-11 at its 5-methylpyridazino[4,5-b] indole moiety by methylation of the corresponding nor-analog with $\left[{ }^{11} \mathrm{C}\right]$ methyl triflate. Its preparation includes the following six stages: (1) trapping at $-40^{\circ} \mathrm{C}$ of $\left[{ }^{11} \mathrm{C}\right]$ methyl triflate (radiosynthesized from cyclotron-produced $\left[{ }^{11} \mathrm{C}\right]$ carbon dioxide via $\left[{ }^{11} \mathrm{C}\right]$ methyl iodide) in $400 \mu \mathrm{l}$ of dimethylformamide containing $0.6-0.9 \mathrm{mg}$ of the precursor for labeling (7-chloro$N, N$-dimethyl-4-oxo-3-phenyl-3,5-dihydro- $4 \mathrm{H}$-pyridazino $[4,5-b]$ indole-1-acetamide) and finely powdered $\mathrm{K}_{2} \mathrm{CO}_{3}(1.5-2.5 \mathrm{mg}$ ); (2) heating the reaction mixture at $120^{\circ} \mathrm{C}$ for $2 \mathrm{~min}$; (3) concentration to dryness under reduced pressure and helium flow; (4) dilution of the residue with 1 $\mathrm{ml}$ of the HPLC mobile phase; (5) HPLC purification on a semi-preparative Waters Symmetry C-18 column (eluent: water/acetonitrile/trifluoroacetic acid, 50:50:0.1, v/v/v); and (6) SepPak Plus cartridge-based removal of the HPLC solvents. $\left[{ }^{11} \mathrm{C}\right]$ SSR180575, as an ethanolic $(15 \%)$ physiological saline solution (4.8-6.7 GBq batches, $10 \mathrm{ml}$ volume), is routinely obtained within 40 min starting from $74 \mathrm{GBq}$ of $\left[{ }^{11} \mathrm{C}\right]$ carbon dioxide (6.5-9.1\% non-decaycorrected overall isolated yields) with specific radioactivities ranging from 37 to $185 \mathrm{GBq} / \mu \mathrm{mol}$.

Quality controls were performed on an aliquot of the ready-to-inject $\left[{ }^{18} \mathrm{~F}\right] \mathrm{DPA}-714$ or $\left[{ }^{11} \mathrm{C}\right]$ SSR180575 preparation, in compliance with our in-house quality control/assurance specifications.

PET imaging. Rats $(502 \pm 59 \mathrm{~g})$ were scanned on a Concorde Focus 220 camera (Siemens) dedicated to small-animal imaging with a spatial resolution of $1.35 \mathrm{~mm}$ full-width at high-maximum. They were imaged within 2-6 months after CNTF injection, using $\left[{ }^{18} \mathrm{~F}\right] \mathrm{DPA}$ $714(n=6)$ or $\left[{ }^{11} \mathrm{C}\right] \mathrm{SSR} 180575(n=4)$ as radioligand. Displacement and presaturation studies with unlabeled PK11195 were also performed on one rat in each group. Solutions of $(R, S)$-PK11195 were freshly prepared by dissolving it in DMSO, followed by dilution, first with polyethylene glycol 400 and then with physiological saline, and were intravenously injected within $2 \mathrm{~h}$. For displacement experiments, unlabeled PK11195 (1 mg/kg) was intravenously injected 15 and $20 \mathrm{~min}$ after injection of $\left[{ }^{18} \mathrm{~F}\right] \mathrm{DPA}-714$ and $\left[{ }^{11} \mathrm{C}\right] \mathrm{SSR} 180575$, respectively. For presaturation experiments, unlabeled PK11195 (2 and $5 \mathrm{mg} / \mathrm{kg}$ for $\left[{ }^{18} \mathrm{~F}\right] \mathrm{DPA}-714$ and $\left[{ }^{11} \mathrm{C}\right] \mathrm{SSR} 180575$, respectively) was intravenously injected $5 \mathrm{~min}$ before injection of radioligands.

Anesthesia was induced with $5 \%$ isoflurane and maintained by $2-2.5 \%$ of isoflurane in $100 \% \mathrm{O}_{2}$. Animals were placed within the scanner using a home-made stereotactic frame compatible with PET acquisition in 
prone position and were kept at $37^{\circ} \mathrm{C}$ using a heating blanket (Harvard Apparatus). Concomitantly with a bolus injection of $\left[{ }^{18} \mathrm{~F}\right] \mathrm{DPA}-714$ or $\left[{ }^{11} \mathrm{C}\right] \mathrm{SSR} 180575(1.83 \pm 0.33$ and $2.00 \pm 0.27 \mathrm{mCi}$, respectively) via a 26-gauge catheter in the tail vein, a 90 min emission scan was performed with an energy window of $400-650 \mathrm{keV}$ and a coincidence time window of 6 ns. The data files for the list-mode acquisition were displayed as 3D sinograms with a maximum ring difference of 47 and a span of 3 . Finally, each emission sinogram was normalized, corrected (for attenuation and radioactivity decay), and reconstructed with a FORE plus OSEM-2D algorithm (16 subsets, four iterations).

Magnetic resonance imaging. Magnetic resonance imaging (MRI) was used to confirm the injection site, to exclude animals with detectable edema at the injection site ( 1 of 10 animals in this study) and to define anatomical regions of interest (ROIs) through PET/MRI coregistration. MRI was performed on a $7 \mathrm{~T}$ horizontal system (Varian-Agilent Technologies) equipped with a gradient coil reaching $600 \mathrm{mT} / \mathrm{m}(120 \mu$ sise time), a radiofrequency birdcage $1 \mathrm{H}$ coil for transmission, and a fourchannel surface receive coil (Rapid Biomedical).

Animals were anesthetized using $2 \%$ isoflurane in $100 \% \mathrm{O}_{2}$ and fixed by mouth and ear bars to a stereotactic MRI-compatible rodent frame. Once in the magnet, animals were heated by a hot air flux, and their temperature and respiration parameters were monitored. T2-weighted images were acquired using a fast spin-echo sequence with the following parameters: TE, $20 \mathrm{~ms}$; TR, $7000 \mathrm{~ms}$; field of view, $38.4 \times 38.4 \mathrm{~mm}$; matrix, $256 \times 256$; resulting in a $150 \times 150 \mu \mathrm{m}$ in-plane resolution; 106 coronal slices with $300 \mu \mathrm{m}$ thickness; sampling spectral width of $90 \mathrm{kHz}$; acquisition time of $37 \mathrm{~min}$.

PET data analysis. PET time frames collected were summed and manually coregistered to the T2-weighted MRI for each animal, using rigid transformations. Coaligned MR images were used to define ROI (left striatum $=$ lenti-LacZ; right striatum = lenti-CNTF), based on anatomical landmarks, using an in-house image processing software (Anatomist, visualization tool of BrainVISA, http://www.brainvisa.info). This process was performed by the same operator for all experiments. ROIs were of $45.54 \pm 3.86$ and $45.48 \pm 5.07 \mathrm{~mm}^{3}$, respectively, for lenti-LacZ- and lenti-CNTF-injected striata. The mean activity concentration values in the left and right ROIs were calculated and used to obtain regional time activity curves (TACs). These curves were then normalized for injected dose and body weight and expressed as percentage standardized uptake values $(\mathrm{SUV}): \% \mathrm{SUV}=[100 \times$ ROI values $(\mathrm{Bq} / \mathrm{ml})] /[($ injected dose $\left.(\mathrm{mCi}) \times 37.10^{6}\right) /$ body weight $\left.(\mathrm{g})\right]$.

Immunohistology. Two to $12 \mathrm{~d}$ after PET scan, rats were killed with an overdose of pentobarbital, and their brains were rapidly collected and frozen in isopentane at $-30^{\circ} \mathrm{C}$. Frozen brains were embedded in a homemade green medium and entirely cut into $20-\mu \mathrm{m}$-thick coronal sections using a cryostat. Every fifth section, a block-face photograph (i.e., picture of the brain surface) was recorded using a digital camera (high in-plane resolution of $30 \times 30 \mu \mathrm{m}^{2}$ ), to serve as a reference for postmortem image $3 \mathrm{D}$ reconstruction. Ten series of tissue sections encompassing the entire striatum were collected and mounted on Superfrost glass slides.

After postfixation of frozen sections in $4 \%$ paraformaldehyde for $4 \mathrm{~h}$, DAB immunohistochemistry was performed with an automated immunostaining system (Ventana-Roche Discovery XT Medical), according to the instructions of the manufacturer. The following primary antibodies were used: GFAP (1:1000; Dako), ED1/CD68 (1:100; Serotec), IBA1 (1: 250; Wako), and vimentin (1:100; Calbiochem). Stained sections were digitized, and staining intensity (measured as optical density after background subtraction) was evaluated in the striatum on six to eight slices per rat, using a computer-based image analysis system (MCID Analysis). The number of IBA1-positive cells was counted under the $40 \times$ objective of a microscope on eight fields of view taken from two sections per rat.

Two additional rats injected with lenti-LacZ and lenti-CNTF, respectively, in the left and right striatum were transcardially perfused with $4 \%$ paraformaldehyde under pentobarbital anesthesia. After immersion for $24 \mathrm{~h}$ in a $20 \%$ sucrose solution, brains were cut into $40 \mu \mathrm{m}$ coronal sections using a freezing microtome. Double or triple fluorescent immunostainings were performed on floating sections as described previously (Escartin et al., 2006). We used primary antibodies directed against GFAP (1:1000; Sigma), IBA1 (1:500), OX42/CD11b (MRC275; 1:1000;
Table 1. CNTF activates astrocytes and has limited effects on other neuroinflammation markers

\begin{tabular}{|c|c|c|c|}
\hline \multirow[b]{2}{*}{ Gene symbol (common name) } & \multirow[b]{2}{*}{ Sequence \# } & \multicolumn{2}{|l|}{ mRNA level } \\
\hline & & Lenti-LacZ & Lenti-CNTF \\
\hline \multicolumn{4}{|l|}{ Astrocytes } \\
\hline Gfap & NM_017009 & $100 \pm 20.95$ & $1272.89 \pm 144.83^{* *}$ \\
\hline Vim (vimentin) & NM_031140 & $100 \pm 23.15$ & $830.81 \pm 121.58^{* *}$ \\
\hline \multicolumn{4}{|l|}{ Microglia } \\
\hline Itgam (CD11b) & NM_012711 & $100 \pm 12.67$ & $165.78 \pm 34.27$ \\
\hline Aif1 (IBA1) & NM_017196 & $100 \pm 13.65$ & $138.95 \pm 12.83$ \\
\hline \multicolumn{4}{|l|}{ Cytokines and chemokines } \\
\hline IL-1a & NM_017019 & $100 \pm 7.71$ & $125.22 \pm 26.98$ \\
\hline IL-6 & NM_012589 & $100 \pm 10.68$ & $97.39 \pm 14.57$ \\
\hline IL-10 & NM_012854 & $100 \pm 19.31$ & $96.26 \pm 21.57$ \\
\hline LIF & NM_022196 & $100 \pm 15.70$ & $82.28 \pm 17.17$ \\
\hline OSM (oncostatin M) & NM_001006961 & $100 \pm 23.39$ & $128.47 \pm 23.40$ \\
\hline $\operatorname{Tnfa}(\operatorname{TNF} \alpha)$ & NM_012675 & $100 \pm 13.04$ & $200.56 \pm 34.05^{*}$ \\
\hline CCl3 (MIP1- $\alpha)$ & NM_013025 & $100 \pm 9.53$ & $57.53 \pm 19.34$ \\
\hline C CI5 (RANTES) & NM_031116 & $100 \pm 29.48$ & $82.54 \pm 34.32$ \\
\hline Cxcl1 (GRO/KC) & NM_030845 & $100 \pm 17.57$ & $61.72 \pm 5.24$ \\
\hline C3 & NM_016994 & $100 \pm 19.54$ & $127.33 \pm 32.83$ \\
\hline \multicolumn{4}{|l|}{ 0xidative stress } \\
\hline Ncf1 (p47phox) & NM_053734 & $100 \pm 13.95$ & $109.77 \pm 17.44$ \\
\hline Ncf2 (p67phox) & XM_344156 & $100 \pm 22.58$ & $95.16 \pm 4.84^{*}$ \\
\hline Nox4 & NM_053524 & $100 \pm 23.74$ & $95.65 \pm 30.43$ \\
\hline Noxa1 & XM_231042 & $100 \pm 29.41$ & $117.65 \pm 11.76^{* *}$ \\
\hline Noxo1 & XM_220221 & $100 \pm 21.74$ & $65.22 \pm 21.76$ \\
\hline $\begin{array}{l}\text { Nos2 (inducible nitric oxide } \\
\text { synthase) }\end{array}$ & NM_012611 & $100 \pm 52.05$ & $76.64 \pm 36.82$ \\
\hline Ptgs1 (Cyclooxygenase 1) & NM_017043 & $100 \pm 8.62$ & $115.52 \pm 8.62$ \\
\hline Ptgs2 (Cyclooxygenase 2) & NM_017232 & $100 \pm 15.46$ & $76.81 \pm 6.76^{* *}$ \\
\hline
\end{tabular}

Analysis by RT-qPCR array of the expression of 22 genes related to neuroinflammation in rats injected with lenti-LacZ or lenti-CNTF. mRNA levels of all genes were normalized to actin mRNA levels and expressed relatively to the LacZ group (set at $100 \%$ ). $n=5 ;{ }^{*} p<0.05,{ }^{* *} p<0.005$, paired $t$ test.

Serotec), TSPO (NP155; a kind gift from Dr. Higuchi, National Institute of Radiological Sciences, Chiba, Japan), and vimentin (ab24525; 1:1000; Abcam). Images of stained sections were taken with a confocal microscope (LSM 510; Carl Zeiss). The TSPO antibody was previously validated by Western blot and immunofluorescence (Ji et al., 2008). Furthermore, negative controls were performed by omission of primary antibodies and produced no significant staining.

Postmortem image registration and $3 D$ reconstruction. Two series of GFAP-labeled histological sections were digitized as 24-bits color images using a high-resolution flatbed scanner (ImageScanner III; GE Healthcare) with a $1200 \mathrm{dpi}$ in-plane resolution $\left(21 \times 21 \mu \mathrm{m}^{2}\right.$, pixel size $)$ to be reconstructed in three dimensions. Image processing was performed using the BrainVISA/Anatomist software package. GFAP histological volume was reconstructed in three dimensions using the photographic volume as geometrical reference, after correction of individual slicespecific 2D deformations. First, block-face photographs were automatically segmented to separate brain tissue from embedding medium, as described previously (Dubois et al., 2007). Series of segmented photographs were then stacked in the $Z$-direction to create a photographic volume of the whole brain spatially coherent (resolution of $0.03 \times 0.03 \times 0.1 \mathrm{~mm}^{3}$ ). Then, digitized GFAP-labeled sections were stacked in the $Z$-direction using BrainRAT module of BrainVISA. Each section of the stacked histological volume, encompassing the striatum, was then coregistered with its corresponding block-face photograph using the Blockmatching registration method (Ourselin et al., 2001). This registration process, based on a $2 \mathrm{D}$ affine transformation, was repeated for all available sections to obtain a spatially consistent GFAP histological volume (resolution of $0.021 \times 0.021 \times 0.1$ $\left.\mathrm{mm}^{3}\right)$.

$R T$ - $q P C R$. Five rats injected with lenti-LacZ and lenti-CNTF in the left and right striatum, respectively, were killed under pentobarbital anesthesia. Rat brains were rapidly collected, and each striatum was dissected out on ice from $1 \mathrm{~mm}$ coronal slices and stored in RNAlater (Sigma) until additional processing. Total RNA was isolated from striatal samples with Trizol (Invitrogen), purified on RNA clean-up columns, and residual 
A

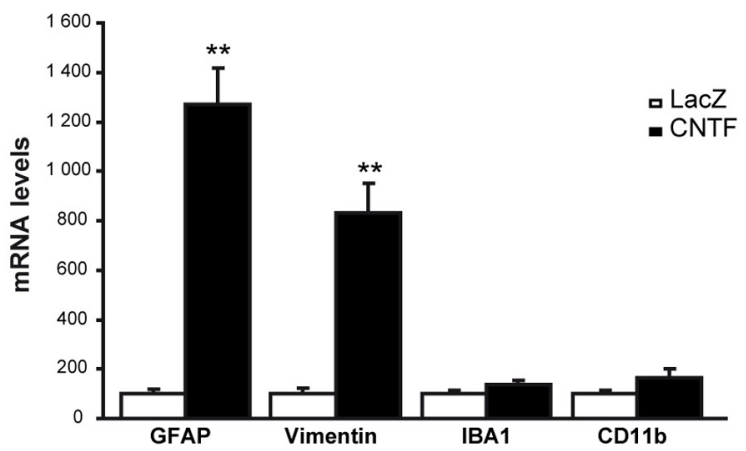

B

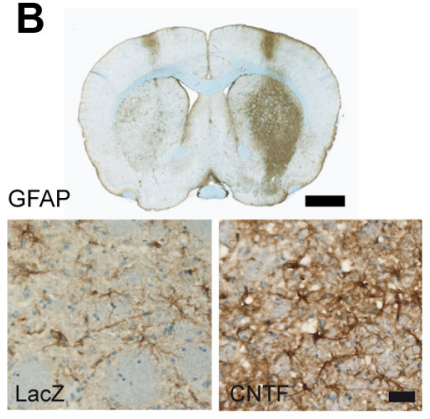

D

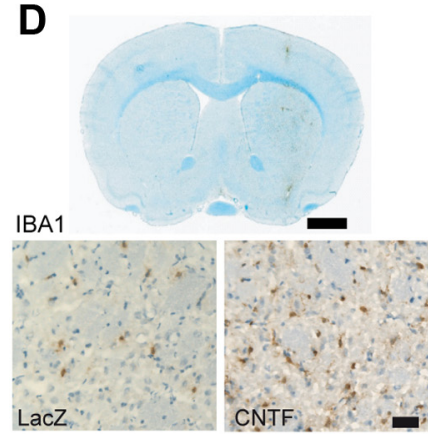

C

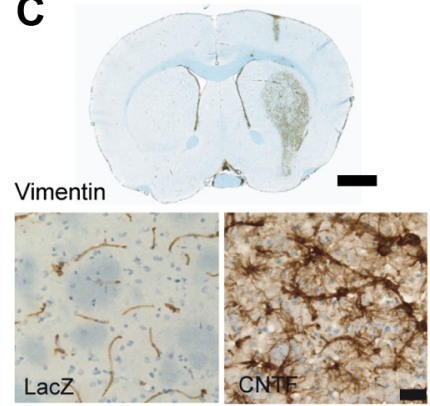

E

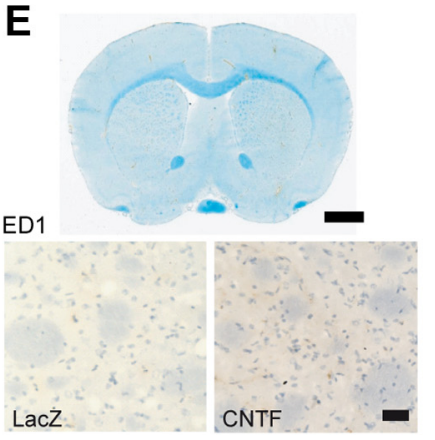

F

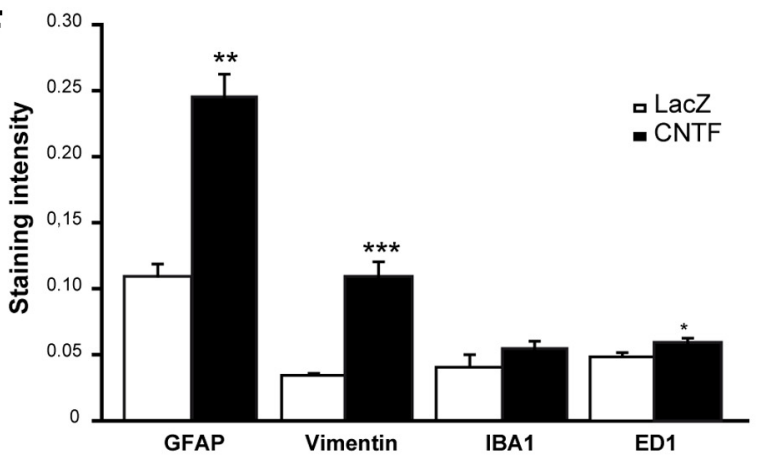

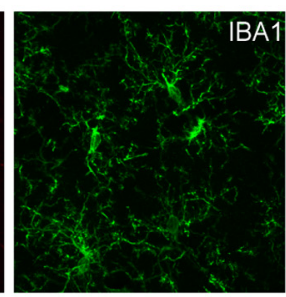
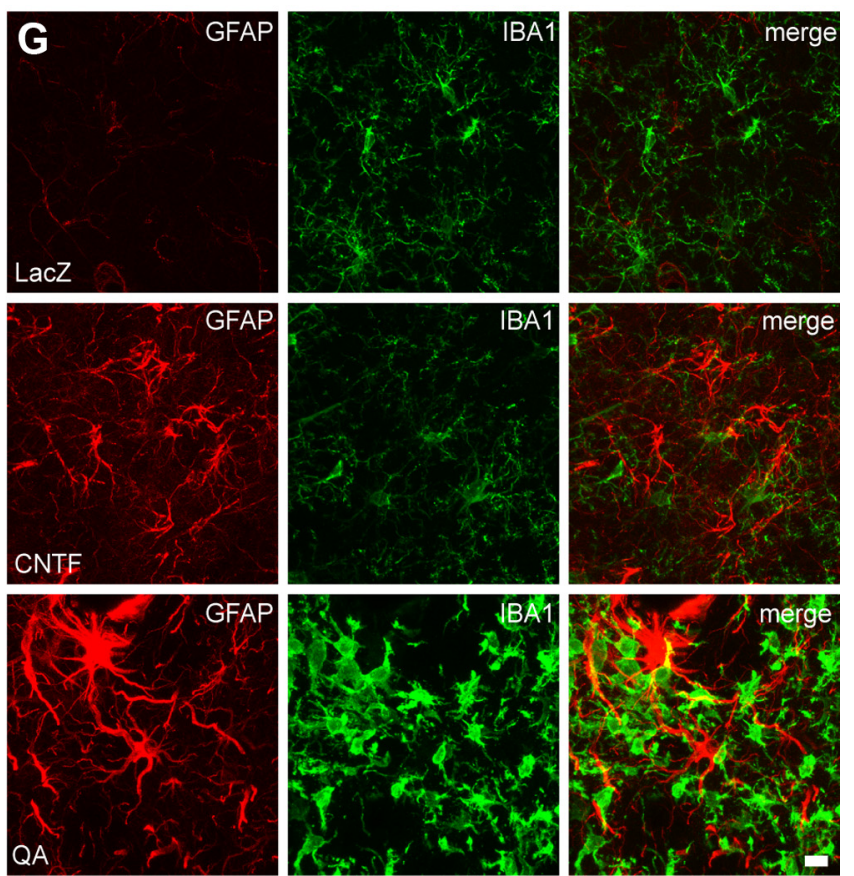

Figure 1. CNTF selectively activates astrocytes. $A, C N T F$ increases mRNA levels of GFAP and vimentin buthas no significant effects on microglia markers IBA1 and CD11b. mRNA levels were normalized to actin and expressed relatively to levels in the LacZ group (set at $100 \%) . n=5 ; * * p<0.005$, paired $t$ test. $\boldsymbol{B}-\boldsymbol{E}$, Immunostainings of rat brains injected with lenti-LacZ and lenti-CNTF in the left and right striatum, respectively. CNTF increases the expression of the astrocyte intermediate filaments GFAP (B) and vimentin ( $\boldsymbol{C}$. At higher magnification, astrocytes display the characteristic reactive hypertrophic morphology (D). Compared with astrocytes, CNTF has limited effects on microglial cells detected by their expression of IBA1.E, ED1/CD68, a selective marker of reactive microglia, is expressed at background level in both striata. Scale bars: $2.5 \mathrm{~mm}$ and $50 \mu \mathrm{m}$. Sections are counterstained with hematoxylin/bluing. $F$, Staining intensity measured in the striatum injected with lenti-LacZ or lenti-CNTF after background subtraction. $n=6$ rats with $6-8$ sections for each rat. ${ }^{*} p<0.05,{ }^{* *} p<0.005,{ }^{* * *} p<0.001$, paired $t$ test. G, Immunofluorescent stainings for GFAP and IBA1 confirm that CNTF induces strong morphological changes in astrocytes but not in microglia compared with the positive control brain injected with QA. Projections of confocal images. Scale bar, $10 \mu \mathrm{m}$.

DNA was digested by on-column treatment with DNase (MachereyNagel). cDNA was synthesized from $0.5 \mu \mathrm{g}$ of RNA using the RT ${ }^{2}$ PCR Array First Strand kit from SABiosciences following the instructions of the manufacturer. cDNA was mixed with the $\mathrm{RT}^{2}$ Real Time SYBR Green PCR mix (SABiosciences) and dispensed in a custom-made qPCR array plate containing specific primers for a gene of interest in each well (see gene list in Table 1). For each sample (i.e., plate), we checked that the three quality controls (absence of contamination with genomic DNA, efficiency of RT and qPCR reactions) were fulfilled, according to the instructions of the manufacturer. Three genes ( $I L-1 \beta, I F N \gamma$, and $C c l 2)$ could not be detected in any or several samples and thus were not analyzed. The abundance of the gene of interest was normalized to the abundance of the housekeeping gene Actin using the $\Delta \mathrm{Ct}$ method. Actin, as well as additional housekeeping genes $(G A P D H, L D H)$ studied on the PCR array plate, were not different between the two groups. An additional qPCR was performed on these striatal cDNA samples using specific primers against rat TSPO (forward primer, GCTGCCCGCTTGCTGTATCCT; reverse primer, CCCTCGCCGACCAGAGTTATCA). TSPO abundance was normalized to the abundance of cyclophilin A in each sample (forward primer, ATGGCAAATGCTGGACCAAA; reverse primer, GCCTTCTTTCACCTTCCCAAA).

Western blots. Three rats injected with lenti-LacZ and lenti-CNTF in the left and right striatum, respectively, were killed under pentobarbital anesthesia. Striata were rapidly dissected out on ice and homogenized in $50 \mathrm{~mm}$ Tris- $\mathrm{HCl}, \mathrm{pH} 7.4,100 \mathrm{~mm} \mathrm{NaCl}$, and $1 \%$ SDS, with protease inhibitor cocktail (Roche). Western blots were performed using ECL detection as described previously (Escartin et al., 2011) using antibodies against actin (1:5000) and TSPO (1:500).

Statistical analysis. Data are expressed as mean \pm SEM. $n$ indicates the number of rats. Left-right comparisons were performed using paired $t$ test. TACs for $\left[{ }^{18} \mathrm{~F}\right] \mathrm{DPA}-714$ and $\left[{ }^{11} \mathrm{C}\right] \mathrm{SSR} 180575$ were analyzed by two-way repeated-measures ANOVA (time, injected side).

\section{Results}

CNTF selectively activates astrocytes

We have reported previously that lentivirus-mediated gene transfer of the cytokine CNTF in the rat striatum activates astrocytes 


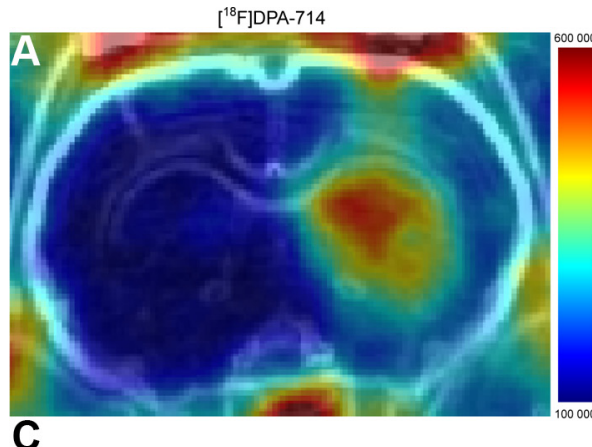

C
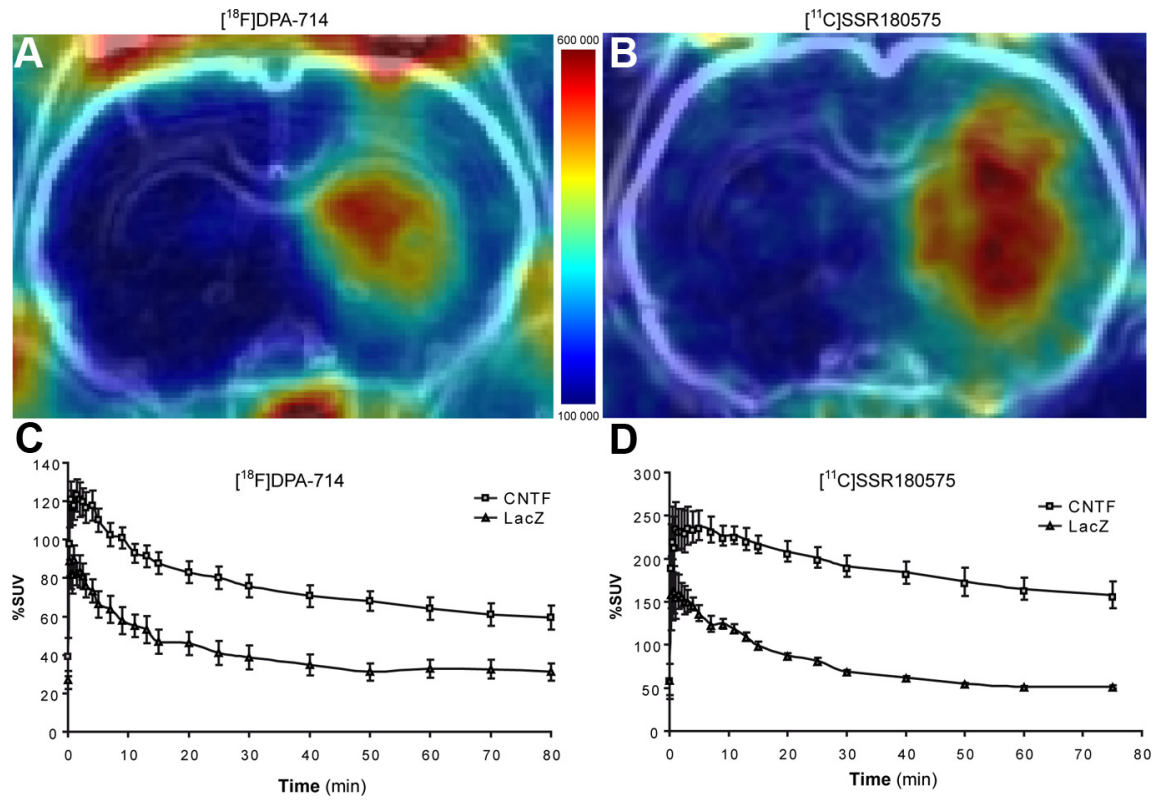

D

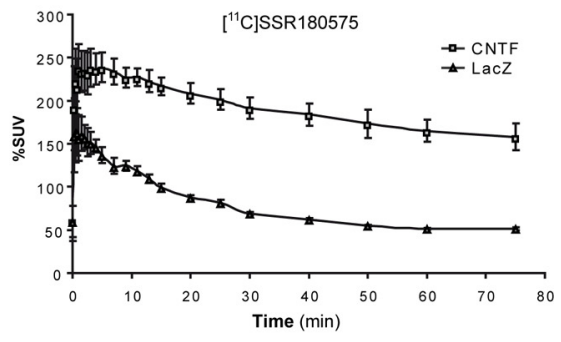

Figure 2. $\quad\left[{ }^{18} \mathrm{~F}\right] \mathrm{DPA}-714$ and $\left[{ }^{11} \mathrm{C}\right] \mathrm{SSR} 180575$ bind to the lenti-CNTF-injected striatum. Coronal rat brain view of \%SUV summed PET images (over $90 \mathrm{~min}$ ) for $\left[{ }^{18} \mathrm{~F}\right] \mathrm{DPA}-714(\boldsymbol{A})$ and $\left[{ }^{11} \mathrm{C}\right]$ SSR180575 (B) after coregistration with the individual MRI. A large area of radioligand binding is observed in the striatum injected with lenti-CNTF for both radioligands. TACs for $\left[{ }^{18} \mathrm{~F}\right] \mathrm{DPA}-714$ $(\boldsymbol{C}, n=6)$ and $\left[{ }^{11} \mathrm{C}\right] S S R 180575(\boldsymbol{D}, n=4)$ in the lenti-CNTF-injected and the contralateral lenti-LacZ-injected striata. TACs are expressed as mean \%SUV. Both radioligands displayed a strong significant difference between the lenti-CNTF and lenti-LacZ striata $\left(p<10^{-4}\right.$ for both radioligands, two-way repeated-measures ANOVA). Color-coded scale is in becquerel/cubic centimeter.

A

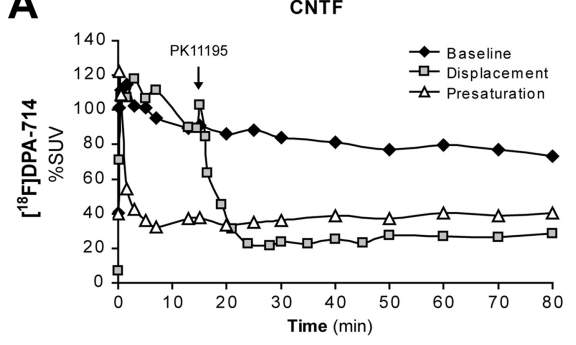

B

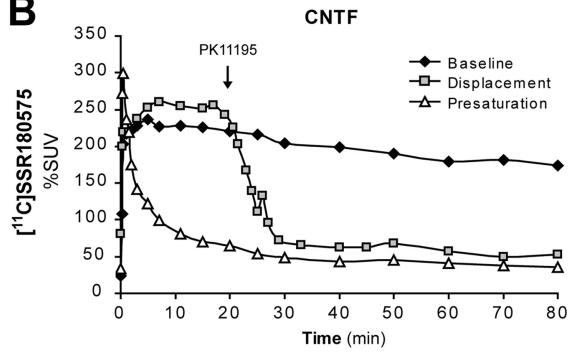

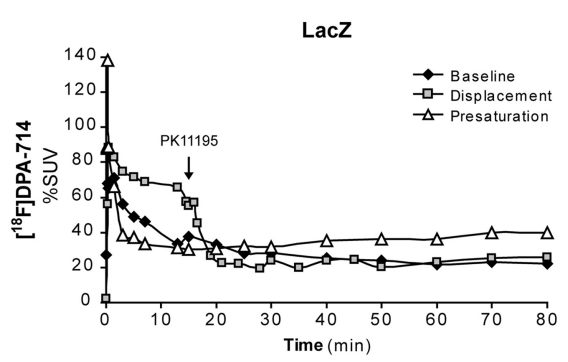

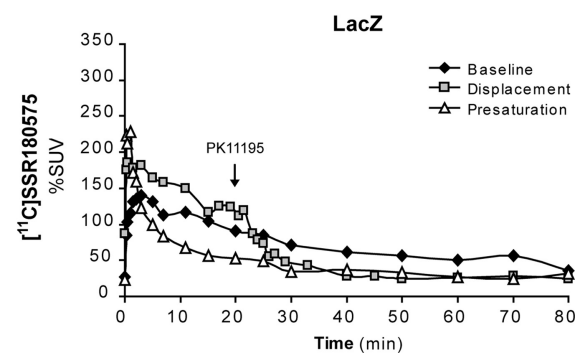

Figure 3. $\quad\left[{ }^{18} \mathrm{~F}\right] \mathrm{DPA}-714$ and $\left[{ }^{11} \mathrm{C}\right] \mathrm{SSR} 180575$ binding is presaturated and displaced by an excess of PK11195. $\boldsymbol{A}, \boldsymbol{B}$, Presaturation of $\left[{ }^{18} \mathrm{~F}\right] \mathrm{DPA}-714$ and $\left[{ }^{11} \mathrm{C}\right] \mathrm{SSR} 180575$ was tested with an injection of, respectively, 2 and $5 \mathrm{mg} / \mathrm{kg} \mathrm{PK11195,} 5 \mathrm{~min}$ before radioligand administration. Displacement of [ $\left.{ }^{18} \mathrm{~F}\right] \mathrm{DPA}-714$ and $\left[{ }^{11} \mathrm{C}\right] \mathrm{SSR} 180575$ was induced by $1 \mathrm{mg} / \mathrm{kg}$ PK11195, respectively, 15 and $20 \mathrm{~min}$ after radioligand administration (arrow). TACs are shown for $\left[{ }^{18} \mathrm{~F}\right] \mathrm{DPA}-714(\boldsymbol{A})$ and $\left[{ }^{11} \mathrm{C}\right]$ SSR180575 $(\boldsymbol{B})$ on both lenti-CNTF and lenti-LaCZ striata. An additional baseline experiment is shown; all three exams were performed on the same rat for each radioligand.

but has no detectable effects on microglia and neurons (Escartin et al., 2006). To further characterize our model of selective activation of astrocytes in the rodent brain, we used RT-qPCR array to quantify the expression of several markers of neuroinflammation (Table 1). The effects of lenti-CNTF were compared with lenti-LacZ, which does not induce neuroinflammation or nonspecific effects in the brain compared with vehicle injection, as demonstrated previously by multiple histological and functional indexes (Escartin et al., 2006, 2007).
Here, we found that CNTF induced a strong expression of two classic markers of astrocyte reactivity: vimentin and GFAP (8.3-fold and 12.7-fold, respectively, vs lenti-LacZ, $p<0.005$, paired $t$ test; Fig. $1 A$, Table 1). In contrast to its strong effect on astrocytes, CNTF did not significantly change the mRNA levels of reactive microglia markers IBAl and CD11b (respectively, 1.4-fold and 1.7fold vs lenti-LacZ, $p>0.05$, paired $t$ test). CNTF also produced a small increase in the mRNA levels of the proinflammatory cytokine TNF $\alpha$ (twofold vs lenti-LacZ rats, $p<0.05$, paired $t$ test) and a significant yet minimal increase in Noxal mRNA levels (1.2-fold vs lenti-LacZ, $p<$ 0.005 , paired $t$ test). Finally, CNTF significantly decreased the expression of $\mathrm{Ncf} 2$ and Ptgs2 (respectively, $p<0.05$ and $p<$ 0.005 , paired $t$ test). Many other neuroinflammation markers, such as cytokines, chemokines, and reactive oxygen speciesproducing enzymes, remained unchanged (Table 1), confirming the selective activation of astrocytes by lenti-CNTF.

Additionally, immunostaining demonstrated that CNTF induced a strong activation of astrocytes and minimal microglial activation. We observed a significant increase in GFAP and vimentin immunoreactivity in the striatum injected with lenti-CNTF (respectively, 2.2-fold and 3.2-fold vs lentiLacZ, $p<0.005$; Fig. $1 B, C, F)$. Consistent with a restricted activation of microglia with lenti-CNTF, there was only a nonsignificant increase in IBA1 staining in the lenti-CNTF-injected striatum (Fig. 1D,F) and a small increase in ED1/CD68, a marker of reactive microglia (1.2-fold, $p<0.05$; Fig. $1 E, F)$. As a positive control, we confirmed that these microglia markers were strongly induced by QA (data not shown), an excitotoxin known to induce significant neuroinflammatory responses (Ryu et al., 2005). We observed an increase in the number of IBA1-positive cells in the lenti-CNTF-injected striatum (1.8fold, $p<0.05$ vs lenti-LacZ) but that remained marginal compared with the one induced by QA (5.9-fold, $p<10^{-5}$; data not shown).

To further analyze morphological changes induced by CNTF in astrocytes and microglia, we used confocal fluorescent microscopy on thicker sections. In the lenti-CNTF-injected striatum, astrocytes displayed typical features of reactivity: they were hypertrophic and expressed high levels of GFAP (Fig. 1G). On the contrary, IBA1-positive microglia displayed a normal resting morphology with thin processes, very different from amoeboid microglia observed in the QA-injected striatum (Fig. $1 G$ ).

The characterization of CNTF effects at the mRNA, protein, and cellular level demonstrated its selective activation of astrocytes with minimal effects on microglia. 
$\left[{ }^{18} \mathrm{~F}\right]$ DPA-714 and $\left[{ }^{11} \mathrm{C}\right]$ SSR 180575 display specific binding to the lenti-CNTF-injected striatum Both $\left[{ }^{18} \mathrm{~F}\right] \mathrm{DPA}-714$ and $\left[{ }^{11} \mathrm{C}\right]$ SSR 180575 displayed an increased uptake in the striatum injected with lenti-CNTF compared with the contralateral side injected with lenti-LacZ (Fig. 2A,B). As shown by the TACs of $\left[{ }^{18} \mathrm{~F}\right] \mathrm{DPA}-714$, the peak was reached within $2 \mathrm{~min}$ after injection on both sides (Fig. 2C). The maximum uptake of $\left[{ }^{11} \mathrm{C}\right]$ SSR180575 appeared as a short plateau, 2-5 min after injection (Fig. 2D). In the lenti-CNTF-injected striatum, maximal uptake of $\left[{ }^{18} \mathrm{~F}\right]$ DPA-714 was followed by a rapid washout $(-30 \%$ of maximal uptake at 20 min after injection). This washout was slower for $\left[{ }^{11} \mathrm{C}\right] \mathrm{SSR} 180575$ ( $-9 \%$ of maximal uptake at 20 min after injection). For both radioligands, wash-in and washout phases were more rapid in the lenti-LacZinjected than in the lenti-CNTF-injected striatum, and pharmacokinetics differed significantly depending on the injected lentivirus (time $\times$ injected side, $p<10^{-4}$, two-way repeated-measures ANOVA). Both radioligands highlighted a strong significant difference between the lenti-CNTF and lentiLacZ side $\left(p<10^{-4}\right.$, two-way repeatedmeasures ANOVA). Within 30 and $90 \mathrm{~min}$ after radioligand administration, the averaged uptake ratio in the lenti-CNTF-injected versus the lenti-LacZ-injected striatum was higher for $\left[{ }^{11} \mathrm{C}\right] \mathrm{SSR} 180575(3.35 \pm 0.87)$ compared with $\left[{ }^{18} \mathrm{~F}\right] \mathrm{DPA}-714(2.29 \pm 0.67)$, although not significantly ( $p=0.09$, unpaired $t$ test).

The binding selectivity for TSPO was tested for each radioligand by presaturation and displacement studies using an excess of the reference ligand PK11195. These experiments were performed on the same rat, using the baseline acquisition as the reference. After presaturation with unlabeled PK11195, the uptake of both radioligands into the striatum was faster and higher than observed in the baseline experiment. A faster washout reduced radioligand uptake to background levels for both sides (Fig. $3 A, B$ ). This higher initial uptake of radioactivity at presaturation with PK11195 is common with TSPO radioligands, because it also blocks peripheral TSPO binding sites, inducing a higher plasma level of the free radioligands (Venneti et al., 2006). Displacement studies were performed by injection of unlabeled PK11195 (1 mg/kg), 15 and 20 min after injection of $\left[{ }^{18} \mathrm{~F}\right] \mathrm{DPA}-714$ and $\left[{ }^{11} \mathrm{C}\right]$ SSR 180575 . Injection of PK11195 induced a fast decline of both $\left[{ }^{18} \mathrm{~F}\right] \mathrm{DPA}-714$ and $\left[{ }^{11} \mathrm{C}\right]$ SSR 180575 binding in the lenti-CNTF-injected striatum (Figs. $3,4)$. Displacement reduced the signal to background level comparable with presaturation but was faster for $\left[{ }^{18} \mathrm{~F}\right] \mathrm{DPA}-714(5 \mathrm{~min})$ than $\left[{ }^{11} \mathrm{C}\right]$ SSR 180575 (10 min) (Fig. 3B). Displacement was observed in both striata, although to a much lesser extent in the lentiLacZ side (Fig. 3).
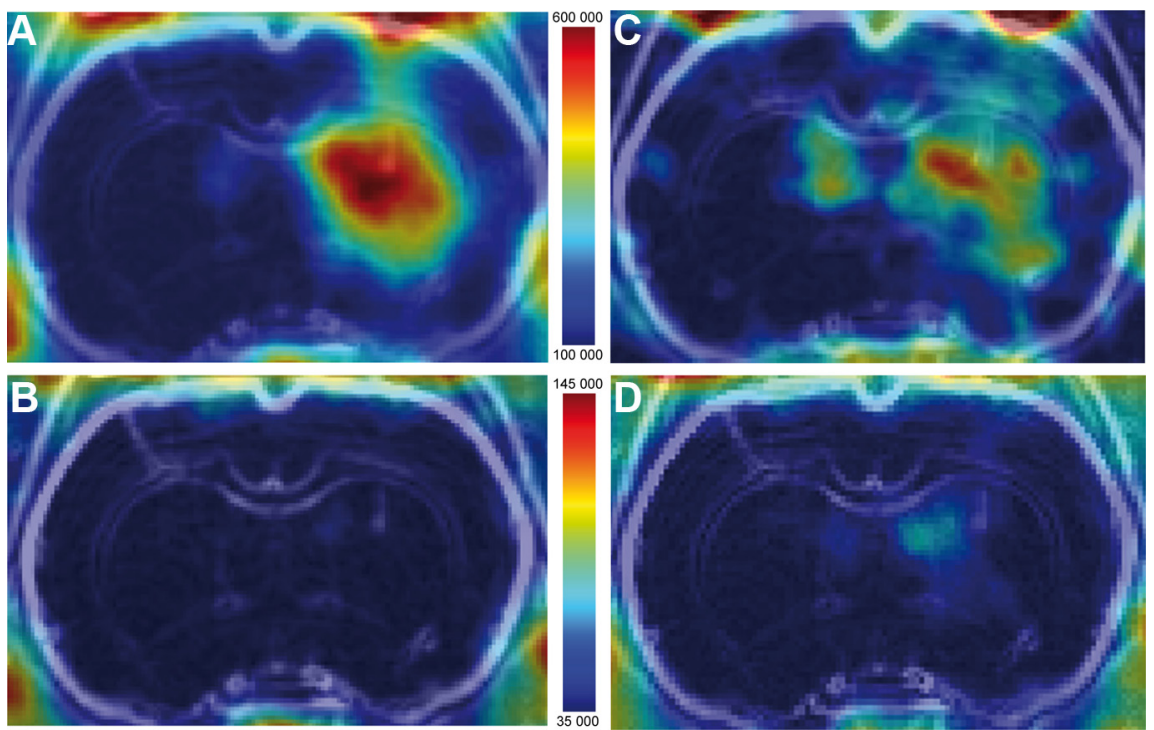

Figure 4. Representative PET images of $\left[{ }^{18} \mathrm{~F}\right] \mathrm{DPA}-714$ presaturation and displacement. Coronal rat brain views of $\left[{ }^{18} \mathrm{~F}\right] \mathrm{DPA}$ 714\% SUV summed PET images (over $90 \mathrm{~min}$ ), coregistered with the individual MRI under baseline $(\boldsymbol{A})$, presaturation $(\boldsymbol{B})$, and displacement conditions (C: \%SUV summed image over first $15 \mathrm{~min} ; \mathbf{D}$ : \%SUV summed image over last $75 \mathrm{~min}$ ). Color-coded scale is in becquerel/cubic centimeter.
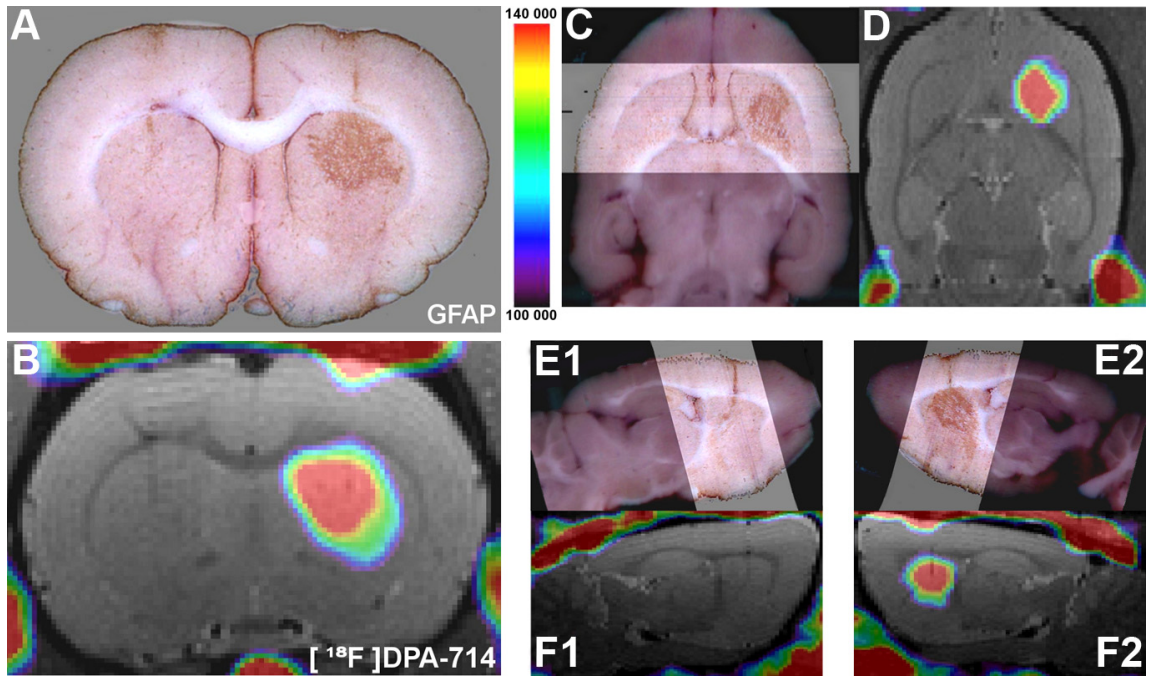

Figure 5. GFAP-positive histological volume matches the radioligand binding volume. Rats were subjected to $\left[{ }^{18} \mathrm{~F}\right] \mathrm{DPA}-714$ PET and MRI scans $(\boldsymbol{B}, \boldsymbol{D}, \boldsymbol{F} \mathbf{F}, \boldsymbol{F 2})$ and had their brains cut and processed for GFAP immunohistochemistry $(\boldsymbol{A}, \boldsymbol{C}, \boldsymbol{E 1}, \mathbf{E 2})$. PET and MRI 3 D images were coregistered to provide fusion images as shown in $\boldsymbol{B}$ (coronal view), $\boldsymbol{D}$ (axial view), $\boldsymbol{F} \boldsymbol{1}$ (left sagittal view), and $\boldsymbol{F} \mathbf{2}$ (right sagittal view). During brain cutting, block-face photographs were taken to reconstruct the postmortem brain in three dimensions and to allow superimposition of digitized and 3D-reconstructed GFAP-stained sections (lighter band in C, E1, E2). A strong correspondence between GFAP-positive histological volume and $\left[{ }^{18} \mathrm{~F}\right] \mathrm{DPA}-714 \mathrm{PET}$ signal is observed in the right striatum injected with lenti-CNTF. Color-coded scale is in becquerels/cubic centimeters.

\section{TSPO is overexpressed by CNTF-activated astrocytes}

To demonstrate that the PET signal in the lenti-CNTF-injected striatum anatomically matches the area immunopositive for GFAP, we reconstructed serial brain sections labeled for GFAP in three dimensions using a block photograph reference volume (see Materials and Methods). Volume of $\left[{ }^{18} \mathrm{~F}\right] \mathrm{DPA}-714$ binding coincided with the GFAP-positive volume (Fig. 5), and a similar pattern was observed for $\left[{ }^{11} \mathrm{C}\right]$ SSR 180575 (data not shown).

To further confirm that the TSPO PET signal originates from CNTF-activated astrocytes, we studied TSPO striatal expression by double immunostaining. We found that TSPO immunoreactivity was increased in the striatum injected with lenti-CNTF, over- 

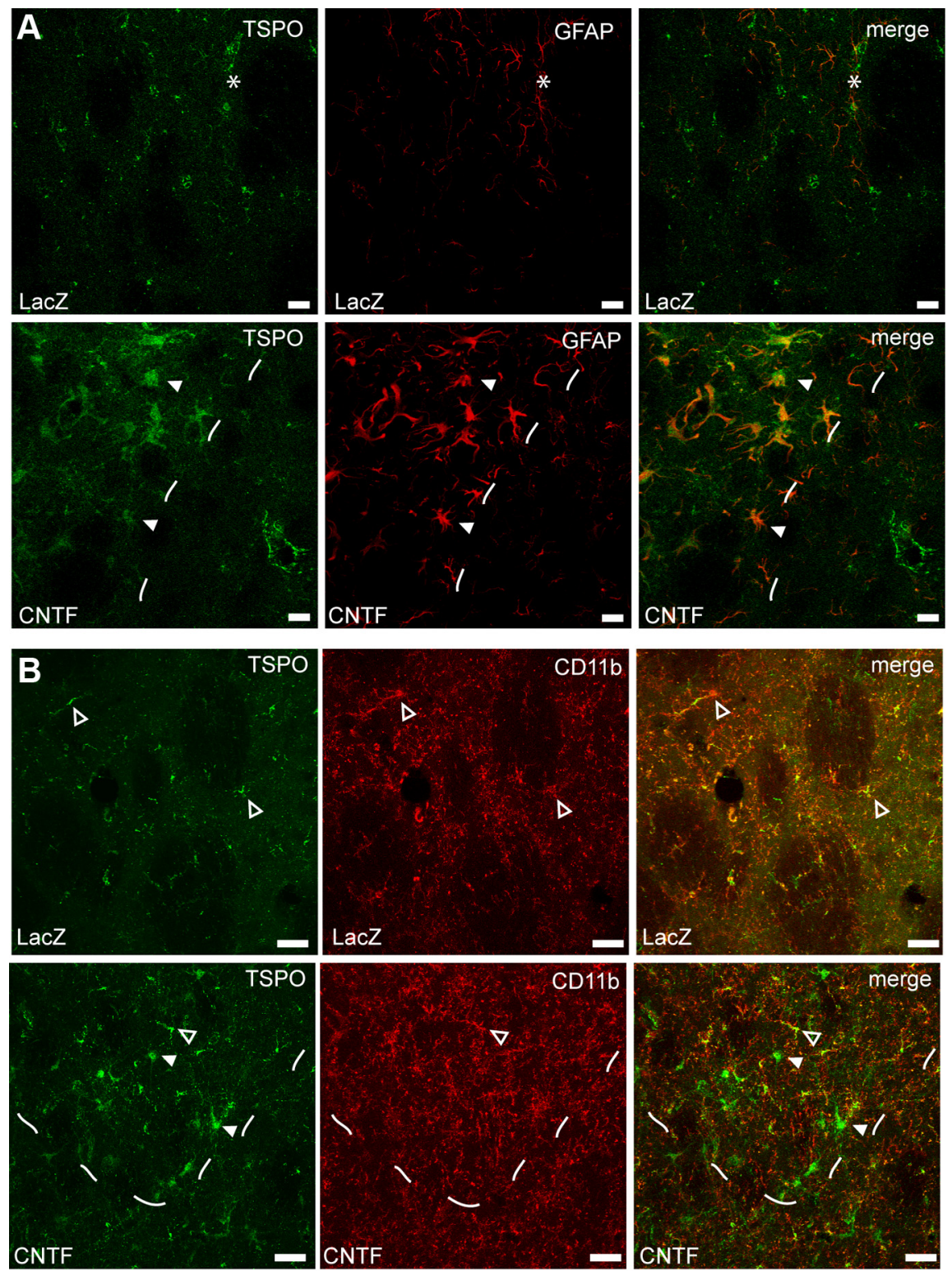

LacZ
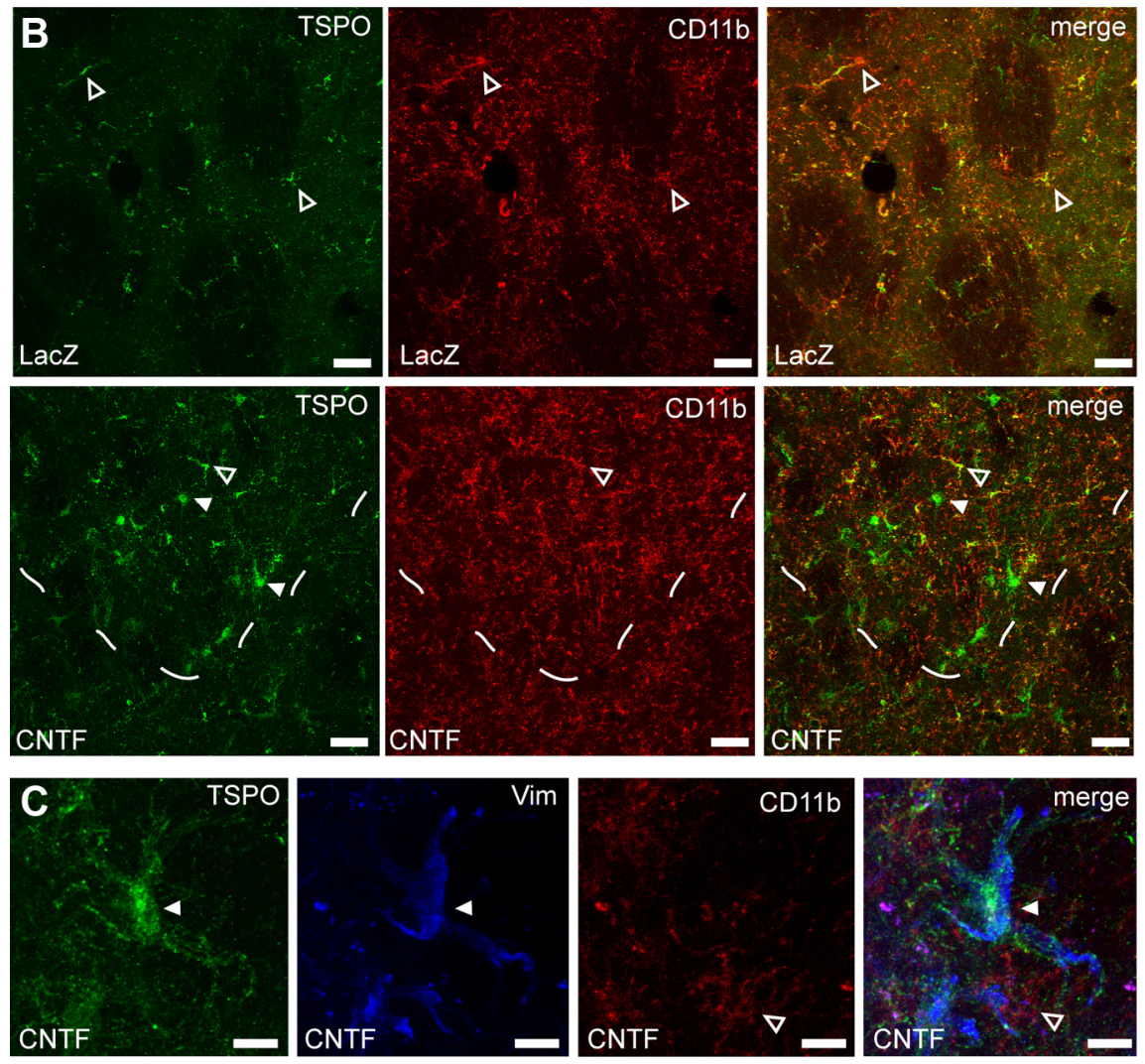

Figure 6. TSPO is overexpressed by CNTF-activated astrocytes. $A$, In the striatum injected with lenti-LacZ, there is a low level of staining for GFAP (red) and TSPO (green). The needle track is indicated by a star. In the striatum injected with lenti-CNTF, TSPO staining is very intense and matches the area displaying GFAP-positive reactive astrocytes (area left to dashes). TSPO is expressed at the highest level in GFAP-positive astrocytes (white arrowhead). Scale bars, $20 \mu \mathrm{m} . \boldsymbol{B}, 0 \mathrm{n}$ the contrary, in the lenti-CNTFinjected striatum, there is only a limited colocalization of TSPO (green) with CD11b-labeled microglia (red, open arrowheads). Such colocalization is also observed in the control striatum injected with lenti-LacZ and gives rise to minimal PET signal. CD11b staining is not visibly enhanced in the area with reactive astrocytes (area above dashes). Scale bars, $20 \mu \mathrm{m}$. C, At higher magnification in the lenti-CNTF-injected striatum, vimentin-positive reactive astrocytes (blue, white arrowhead) express high level of TSPO (green) contrary to CD11b-labeled microglia (red, open arrowhead) that express undetectable levels of TSPO. Scale bars, $10 \mu \mathrm{m}$.

lapping the GFAP-positive area (Fig. 6A). Cells that overexpressed TSPO in the lenti-CNTF-injected striatum were strongly immunoreactive for GFAP (Fig. 6A). On the contrary, there was only minimal colocalization of TSPO with CD11b-positive microglia in the same area (Fig. 6B). In the contralateral side injected with lenti-LacZ, GFAP and TSPO staining were minimal (Fig. 6A). This basal TSPO staining perfectly colocalized with CD11b staining, suggesting that TSPO is expressed at a low level in resting microglia (Fig. $6 B$ ). A triple immunostaining against TSPO, CD11b, and vimentin confirmed that TSPO was overexpressed in CNTFactivated astrocytes (Fig. 6C).

To evaluate whether the increase in TSPO expression in reactive astrocytes originates from an increase at the mRNA level, we performed RT-qPCR in rats injected with lenti-LacZ and lenti-CNTF in the left and right striatum, respectively. CNTF induced a fourfold increase in TSPO mRNA levels $(p<0.05$, paired $t$ test; Fig. 7A). Importantly, TSPO mRNA levels were similar in lenti-LacZ controls and non-injected controls (data not shown). We finally performed Western blots on striatal protein homogenates to evaluate TSPO protein levels by densitometry. TSPO levels (normalized to actin) were significantly increased by CNTF, by a factor of 6 ( $p<0.05$, paired $t$ test; Fig. $7 A, B)$.

\section{Discussion}

Using a unique in vivo model of selective activation of astrocytes, we demonstrate that reactive astrocytes overexpress TSPO at the mRNA and protein level, which is specifically detected by PET imaging using $\left[{ }^{18} \mathrm{~F}\right] \mathrm{DPA}-714$ and $\left[{ }^{11} \mathrm{C}\right]$ SSR 180575 radioligands.

The CNTF model of astrocyte activation is an original and relevant model to assess reactive astrocyte function in vivo. Indeed, CNTF, whose levels increase in several pathological conditions (Ip et al., 1993; Haas et al., 2004), binds to a tripartite receptor partially shared with many other cytokines and activates the JAKSTAT3 pathway (Escartin et al., 2006). This is a central signaling pathway known to be involved in astrocyte activation (Okada et al., 2006; Herrmann et al., 2008). Our model is thus relevant to many pathological situations in which astrocytes become reactive during stimulation of the JAK-STAT3 pathway. There are several additional assets to this model, especially in the context of PET studies: (1) CNTF produces a widespread activation of astrocytes throughout the striatum that is compatible with the PET spatial resolution; (2) neurons and the blood-brain barrier remain unaltered and display normal anatomical and functional features (Escartin et al., 2006; Beurrier et al., 2010; and data not shown); (3) the contralateral hemisphere can serve as a control (being injected with lenti- 
A

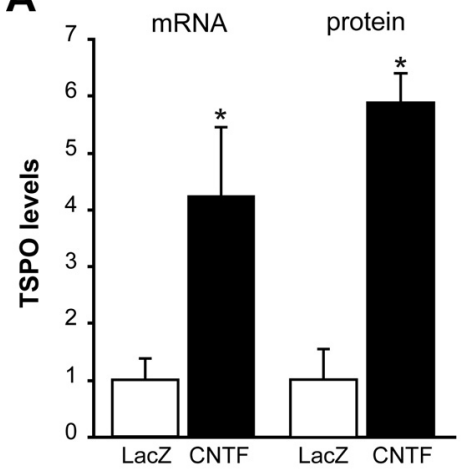

B

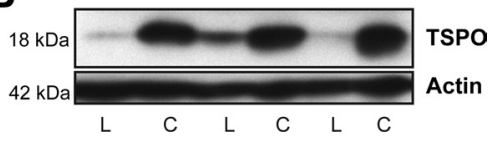

Figure 7. TSPO expression is increased by CNTF. Striatal samples from rats injected with lenti-LacZ (LacZ, L) and lenti-CNTF (CNTF, C) in the left and right striatum, respectively, were analyzed by RT-qPCR and Western blot. A, CNTF significantly increases TSPO expression. TSPO mRNA and protein levels were normalized to cyclophilin and actin, respectively, and expressed relatively to levels in the LacZ group (set at 1). $n=5$ and $n=3$, respectively; ${ }^{*} p<0.05$, paired $t$ test. $\boldsymbol{B}$, Representative Western blot for TSPO.

LacZ), eliminating key bias for PET imaging, such as variability in age, weight, peripheral metabolism of radioligands, and other source of interindividual variations; and finally (4) activation of astrocytes is stable over time, from 15 days to at least 6 months after injection of lenti-CNTF (Escartin et al., 2006), allowing multiple imaging sessions on the same animal.

The transcriptional regulation of TSPO has rarely been evaluated in PET studies. Here, we report for the first time that CNTF induces a fourfold increase in TSPO mRNA levels. This is consistent with other models of neuroinflammation, including degeneration of the entorhinal-hippocampal perforant path (threefold increase; Pedersen et al., 2006) or focal cerebral ischemia (threefold increase; Rojas et al., 2007). CNTF overexpression in the striatum activates STAT3-dependent transcription. The TSPO promoter contains conserved binding sequences for STAT3 in rodents and humans (Batarseh and Papadopoulos, 2010), which could mediate the transcriptional induction of TSPO by CNTF. One of the first TSPO-selective PET radioligand to be developed and characterized for neuroinflammation imaging was $\left[{ }^{11} \mathrm{C}\right]$ (R)-PK11195 (Venneti et al., 2006; Chauveau et al., 2008). However, $\left[{ }^{11} \mathrm{C}\right]-(R)-\mathrm{PK} 11195$ displays some limitations in vivo that motivated the development of new TSPO radioligands. Multiple candidate molecules have been generated, including the indolacetamide $\left[{ }^{11} \mathrm{C}\right] \mathrm{SSR} 180575$ and the pyrazolopyrimidineacetamide [ ${ }^{18} \mathrm{~F}$ ]DPA-714 (Chauveau et al., 2008; Dollé et al., 2009). $\left[{ }^{18} \mathrm{~F}\right] \mathrm{DPA}-714$ has been mainly evaluated and quantified in rat models of excitotoxicity (Chauveau et al., 2009) and cerebral ischemia (Martín et al., 2010), whereas [ ${ }^{11} \mathrm{C}$ ]SSR180575 has only been evaluated once in a rat model of excitotoxicity (Chauveau et al., 2011). In addition, $\left[{ }^{18} \mathrm{~F}\right] \mathrm{DPA}-714$ was studied in the healthy primate and displayed marked uptake in TSPOrich organs and specific binding in the brain as demonstrated using PK11195 (James et al., 2008). [ $\left.{ }^{18} \mathrm{~F}\right] \mathrm{DPA}-714$ has been studied recently in healthy human subjects (Arlicot et al., 2012) and is currently evaluated in phase I-II clinical trials in Alzheimer's disease and amyotrophic lateral sclerosis patients (Clinical Trials NCT01009359 and NCT00563537).
In our model, the two TSPO radioligands demonstrated a significantly increased and specific binding in the lenti-CNTF-injected striatum. The uptake ratio between the lenti-CNTF- and lenti-LacZinjected striata was not significantly different between $\left[{ }^{18} \mathrm{~F}\right] \mathrm{DPA}-$ 714 and $\left[{ }^{11} \mathrm{C}\right]$ SSR 180575 (respectively, 2.29 and 3.35). Both radioligands were sensitive to presaturation and displacement with unlabeled competitive PK11195 ligand. $\left[{ }^{18} \mathrm{~F}\right] \mathrm{DPA}-714$ and $\left[{ }^{11} \mathrm{C}\right]$ SSR180575 were completely displaced from the CNTF-injected striatum, reaching within minutes the uptake level measured after presaturation with PK11195.

Interestingly, we detected a low binding level of both TSPO radioligands in the control, lenti-LacZ-injected striatum that was also sensitive to presaturation and displacement with unlabeled PK11195, as described previously for $\left[{ }^{11} \mathrm{C}\right] \mathrm{SSR} 180575$ (Chauveau et al., 2011). This basal expression of TSPO was confirmed by RT-qPCR and was similar to the one found in non-injected controls. Using double stainings, we observed that expression of TSPO was restricted to resting microglia in the control brain. Despite this detectable basal expression of TSPO, it was still possible to demonstrate a significant increase in radioligand binding in the lenti-CNTF striatum.

The cellular origin of the signal detected by TSPO radioligands is debated, but it is generally admitted that TSPO PET imaging reflects microglial activation in brain disease models or in patients (Cagnin et al., 2002; Venneti et al., 2006, 2009; Politis and Piccini, 2012). This is originally based on the observation that the temporal profiles of microglial activation and TSPO radioligand binding correlate well, as assessed by ex vivo autoradiography (Myers et al., 1991; Pedersen et al., 2006; Maeda et al., 2007; Venneti et al., 2007). However, using a model of hippocampal neurotoxicity, a landmark study reported that reactive astrocytes also overexpress TSPO and could contribute to TSPO radioligand binding ex vivo (Kuhlmann and Guilarte, 2000). This was later confirmed in other models (Chen et al., 2004; Chen and Guilarte, 2006; Maeda et al., 2007; Martín et al., 2010), but to our knowledge, only two in vivo studies have reported that reactive astrocytes overexpress TSPO to levels detectable by PET imaging (Rojas et al., 2007; Ji et al., 2008). However, the models used (middle cerebral artery occlusion and cuprizone intoxication) induce complex pathological effects, such as blood-brain barrier alteration, neuronal death, demyelination, and some levels of microglia activation. Such effects could impact the resultant PET signal. In our study, we aimed at isolating the contribution of reactive astrocytes to the TSPO PET signal by selectively activating astrocytes in the normal rat brain, in the absence of additional pathological processes. We were able to demonstrate that reactive astrocytes by themselves overexpress TSPO and provide a significant binding of TSPO radioligand in vivo.

Our findings indicate that, in complex pathological states (neurodegenerative diseases, traumatic brain injury, or stroke) associated with both reactive astrocytes and microglia, the observed TSPO signal may well originate from either one or both cell types. Therefore, in the absence of postmortem immunohistological analysis, caution must be used to interpret the cellular origin of the TSPO PET signal and, thus, the influence of reactive glial cells on disease progression. Indeed, astrocytes and microglia play very different roles in the brain: astrocytes provide trophic support to neurons, promote metabolic and ionic homoeostasis, and regulate synaptic transmission, whereas microglial cells are responsible for innate immune response and phagocytosis. Reactive astrocytes are known to promote neuroprotection against excitotoxic, metabolic, oxidative, or even mechanical injuries (Escartin and Bonvento, 2008; Hamby and 
Sofroniew, 2010). In particular, CNTF-activated astrocytes protect neurons against glutamate outflow (Escartin et al., 2006; Beurrier et al., 2010) and metabolic deficits (Escartin et al., 2007). The effect of reactive microglia on neuronal survival is more complex and controversial (Hanisch and Kettenmann, 2007). Although these cells may have beneficial effects, they typically produce high levels of pro-toxic cytokines and reactive oxygen species. It was proposed that TSPO-positive reactive astrocytes participate in a beneficial response, in contrast to TSPO-positive microglial cells that mediate more detrimental effects on neurons (Ji et al., 2008).

There is now a multitude of TSPO radioligands available with different characteristics in terms of chemical classes, pharmacokinetics, peripheral metabolism, and specificity toward TSPO (Chauveau et al., 2008; Dollé et al., 2009). It could be interesting to screen these radioligands for their capacity to discriminate between TSPO expressed by reactive astrocytes and reactive microglia, taking advantage of the CNTF model or similar models of cell-specific activation. Alternative imaging approaches may also enable discrimination of reactive astrocytes from reactive microglia, based on the preferential expression of specific proteins by either cell type. Monoamine oxidase B radioligands (Johansson et al., 2007) or labeled mGluR5 agonists (Drouin-Ouellet et al., 2011) are two possible candidates for PET imaging of reactive astrocytes and microglia, respectively, but they need to be explored further.

Developing non-invasive imaging techniques to monitor neuroinflammation at the cellular level remains a crucial goal. It would contribute to the evaluation of disease models and therapeutic strategies in animals, as well as the diagnosis and monitoring of various brain diseases in patients. Accurate assessment of available PET radioligands, using appropriate models of neuroinflammation like the one presented here, is a prerequisite toward this goal.

\section{References}

Arlicot N, Vercouillie J, Ribeiro MJ, Tauber C, Venel Y, Baulieu JL, Maia S, Corcia P, Stabin MG, Reynolds A, Kassiou M, Guilloteau D (2012) Initial evaluation in healthy humans of $\left[{ }^{18} \mathrm{~F}\right] \mathrm{DPA}-714$, a potential PET biomarker for neuroinflammation. Nucl Med Biol 39:570-578.

Batarseh A, Papadopoulos V (2010) Regulation of translocator protein 18 $\mathrm{kDa}$ (TSPO) expression in health and disease states. Mol Cell Endocrinol 327:1-12.

Beurrier C, Faideau M, Bennouar KE, Escartin C, Kerkerian-Le Goff L, Bonvento G, Gubellini P (2010) Ciliary neurotrophic factor protects striatal neurons against excitotoxicity by enhancing glial glutamate uptake. PLoS One 5:e8550.

Cagnin A, Gerhard A, Banati RB (2002) In vivo imaging of neuroinflammation. Eur Neuropsychopharmacol 12:581-586.

Chauveau F, Boutin H, Van Camp N, Doll é F, Tavitian B (2008) Nuclear imaging of neuroinflammation: a comprehensive review of $\left[{ }^{11} \mathrm{C}\right] \mathrm{PK} 11195$ challengers. Eur J Nucl Med Mol Imaging 35:2304-2319.

Chauveau F, Van Camp N, Doll é F, Kuhnast B, Hinnen F, Damont A, Boutin H, James M, Kassiou M, Tavitian B (2009) Comparative evaluation of the translocator protein radioligands 11C-DPA-713, 18F-DPA-714, and 11C-PK11195 in a rat model of acute neuroinflammation. J Nucl Med 50:468-476.

Chauveau F, Boutin H, Van Camp N, Thominiaux C, Hantraye P, Rivron L, Marguet F, Castel MN, Rooney T, Benavides J, Doll é F, Tavitian B (2011) In vivo imaging of neuroinflammation in the rodent brain with $\left[{ }^{11} \mathrm{C}\right]$ SSR180575, a novel indoleacetamide radioligand of the translocator protein (18 kDa). Eur J Nucl Med Mol Imaging 38:509-514.

Chen MK, Guilarte TR (2006) Imaging the peripheral benzodiazepine receptor response in central nervous system demyelination and remyelination. Toxicol Sci 91:532-539.

Chen MK, Guilarte TR (2008) Translocator protein $18 \mathrm{kDa}$ (TSPO): molecular sensor of brain injury and repair. Pharmacol Ther 118:1-17.
Chen MK, Baidoo K, Verina T, Guilarte TR (2004) Peripheral benzodiazepine receptor imaging in CNS demyelination: functional implications of anatomical and cellular localization. Brain 127:1379-1392.

Damont A, Hinnen F, Kuhnast B, Schollhorn-Peyronneau MA, James M, Luus C, Tavitian B, Kassiou M, Dolle F (2008) Radiosynthesis of $\left[{ }^{18} \mathrm{~F}\right] \mathrm{DPA}-714$, a selective radioligand for imaging the translocator protein $(18 \mathrm{kDa})$ with PET. J Labelled Comp Radiopharm 51:286-292.

Dollé F, Luus C, Reynolds A, Kassiou M (2009) Radiolabelled molecules for imaging the translocator protein $(18 \mathrm{kDa})$ using positron emission tomography. Curr Med Chem 16:2899-2923.

Drouin-Ouellet J, Brownell AL, Saint-Pierre M, Fasano C, Emond V, Trudeau LE, Lévesque D, Cicchetti F (2011) Neuroinflammation is associated with changes in glial mGluR5 expression and the development of neonatal excitotoxic lesions. Glia 59:188-199.

Dubois A, Dauguet J, Herard AS, Besret L, Duchesnay E, Frouin V, Hantraye P, Bonvento G, Delzescaux T (2007) Automated three-dimensional analysis of histological and autoradiographic rat brain sections: application to an activation study. J Cereb Blood Flow Metab 27:1742-1755.

Escartin C, Bonvento G (2008) Targeted activation of astrocytes: a potential neuroprotective strategy. Mol Neurobiol 38:231-241.

Escartin C, Brouillet E, Gubellini P, Trioulier Y, Jacquard C, Smadja C, Knott GW, Kerkerian-Le Goff L, Déglon N, Hantraye P, Bonvento G (2006) Ciliary neurotrophic factor activates astrocytes, redistributes their glutamate transporters GLAST and GLT-1 to raft microdomains, and improves glutamate handling in vivo. J Neurosci 26:5978-5989.

Escartin C, Pierre K, Colin A, Brouillet E, Delzescaux T, Guillermier M, Dhenain M, Déglon N, Hantraye P, Pellerin L, Bonvento G (2007) Activation of astrocytes by CNTF induces metabolic plasticity and increases resistance to metabolic insults. J Neurosci 27:7094-7104.

Escartin C, Won SJ, Malgorn C, Auregan G, Berman AE, Chen PC, Déglon N, Johnson JA, Suh SW, Swanson RA (2011) Nuclear factor erythroid 2-related factor 2 facilitates neuronal glutathione synthesis by upregulating neuronal excitatory amino acid transporter 3 expression. J Neurosci 31:7392-7401.

Haas SJ, Ahrens A, Petrov S, Schmitt O, Wree A (2004) Quinolinic acid lesions of the caudate putamen in the rat lead to a local increase of ciliary neurotrophic factor. J Anat 204:271-281.

Hamby ME, Sofroniew MV (2010) Reactive astrocytes as therapeutic targets for CNS disorders. Neurotherapeutics 7:494-506.

Hanisch UK, Kettenmann H (2007) Microglia: active sensor and versatile effector cells in the normal and pathologic brain. Nat Neurosci 10:1387-1394.

Herrmann JE, Imura T, Song B, Qi J, Ao Y, Nguyen TK, Korsak RA, Takeda K, Akira S, Sofroniew MV (2008) STAT3 is a critical regulator of astrogliosis and scar formation after spinal cord injury. J Neurosci 28:7231-7243.

Ip NY, Wiegand SJ, Morse J, Rudge JS (1993) Injury-induced regulation of ciliary neurotrophic factor mRNA in the adult rat brain. Eur J Neurosci 5:25-33.

James ML, Fulton RR, Vercoullie J, Henderson DJ, Garreau L, Chalon S, Dolle F, Costa B, Selleri S, Guilloteau D, Kassiou M (2008) DPA-714, a new translocator protein-specific ligand: synthesis, radiofluorination, and pharmacologic characterization. J Nucl Med 49:814-822.

Ji B, Maeda J, Sawada M, Ono M, Okauchi T, Inaji M, Zhang MR, Suzuki K, Ando K, Staufenbiel M, Trojanowski JQ, Lee VM, Higuchi M, Suhara T (2008) Imaging of peripheral benzodiazepine receptor expression as biomarkers of detrimental versus beneficial glial responses in mouse models of Alzheimer's and other CNS pathologies. J Neurosci 28:12255-12267.

Johansson A, Engler H, Blomquist G, Scott B, Wall A, Aquilonius SM, Långström B, Askmark H (2007) Evidence for astrocytosis in ALS demonstrated by $\left[{ }^{11} \mathrm{C}\right](\mathrm{L})$-deprenyl-D2 PET. J Neurol Sci 255:17-22.

Kuhlmann AC, Guilarte TR (2000) Cellular and subcellular localization of peripheral benzodiazepine receptors after trimethyltin neurotoxicity. J Neurochem 74:1694-1704.

Maeda J, Higuchi M, Inaji M, Ji B, Haneda E, Okauchi T, Zhang MR, Suzuki K, Suhara T (2007) Phase-dependent roles of reactive microglia and astrocytes in nervous system injury as delineated by imaging of peripheral benzodiazepine receptor. Brain Res 1157:100-111.

Martín A, Boisgard R, Théz é B, Van Camp N, Kuhnast B, Damont A, Kassiou M, Doll é F, Tavitian B (2010) Evaluation of the PBR/TSPO radioligand $\left[{ }^{18} \mathrm{~F}\right] \mathrm{DPA}-714$ in a rat model of focal cerebral ischemia. J Cereb Blood Flow Metab 30:230-241.

Myers R, Manjil LG, Cullen BM, Price GW, Frackowiak RS, Cremer JE 
(1991) Macrophage and astrocyte populations in relation to $\left[{ }^{3} \mathrm{H}\right] \mathrm{PK}$ 11195 binding in rat cerebral cortex following a local ischaemic lesion. J Cereb Blood Flow Metab 11:314-322.

Okada S, Nakamura M, Katoh H, Miyao T, Shimazaki T, Ishii K, Yamane J, Yoshimura A, Iwamoto Y, Toyama Y, Okano H (2006) Conditional ablation of Stat3 or Socs3 discloses a dual role for reactive astrocytes after spinal cord injury. Nat Med 12:829-834.

Ourselin S, Roche A, Subsol G, Pennec X, Ayache N (2001) Reconstructing a 3D structure from serial histological sections. Image Vis Comput 19:25-31.

Pedersen MD, Minuzzi L, Wirenfeldt M, Meldgaard M, Slidsborg C, Cumming P, Finsen B (2006) Up-regulation of PK11195 binding in areas of axonal degeneration coincides with early microglial activation in mouse brain. Eur J Neurosci 24:991-1000.

Politis M, Piccini P (2012) Positron emission tomography imaging in neurological disorders. J Neurol. Advance online publication. Accessed June 24, 2012. doi:10.1007/s00415-012-6428-3.

Rojas S, Martín A, Arranz MJ, Pareto D, Purroy J, Verdaguer E, Llop J, Gómez V, Gispert JD, Millán O, Chamorro A, Planas AM (2007) Imaging brain inflammation with $\left[{ }^{11} \mathrm{C}\right] \mathrm{PK} 11195$ by PET and induction of the peripheral-type benzodiazepine receptor after transient focal ischemia in rats. J Cereb Blood Flow Metab 27:1975-1986.

Rupprecht R, Papadopoulos V, Rammes G, Baghai TC, Fan J, Akula N, Groyer G, Adams D, Schumacher M (2010) Translocator protein (18
$\mathrm{kDa})(\mathrm{TSPO})$ as a therapeutic target for neurological and psychiatric disorders. Nat Rev Drug Discov 9:971-988.

Ryu JK, Choi HB, McLarnon JG (2005) Peripheral benzodiazepine receptor ligand PK11195 reduces microglial activation and neuronal death in quinolinic acid-injected rat striatum. Neurobiol Dis 20:550-561.

Thominiaux C, Damont A, Kuhnast B, Demphel S, Le Helleix S, Boisnard S, Rivron L, Chauveau F, Boutin H, Van Camp N, Boisgard R, Roy S, Allen J, Rooney T, Benavides J, Hantraye P, Tavitian B, Dolle F (2010) Radiosynthesis of 7-chloro- $N, N$-dimethyl-5-[ $\left.{ }^{11} \mathrm{C}\right]$ methyl-4-oxo-3-phenyl-3,5-dihydro-4 $H$-pyridazino[4,5-b]indole-1-acetamide, $\left[{ }^{11} \mathrm{C}\right] S S R 180575$, a novel radioligand for imaging the TSPO (peripheral benzodiazepine receptor) with PET. J Labelled Comp Radiopharm 53:767-773.

Venneti S, Lopresti BJ, Wiley CA (2006) The peripheral benzodiazepine receptor (Translocator protein $18 \mathrm{kDa}$ ) in microglia: from pathology to imaging. Prog Neurobiol 80:308-322.

Venneti S, Lopresti BJ, Wang G, Slagel SL, Mason NS, Mathis CA, Fischer ML, Larsen NJ, Mortimer AD, Hastings TG, Smith AD, Zigmond MJ, Suhara T, Higuchi M, Wiley CA (2007) A comparison of the high-affinity peripheral benzodiazepine receptor ligands DAA1106 and (R)-PK11195 in rat models of neuroinflammation: implications for PET imaging of microglial activation. J Neurochem 102:2118-2131.

Venneti S, Wiley CA, Kofler J (2009) Imaging microglial activation during neuroinflammation and Alzheimer's disease. J Neuroimmune Pharmacol $4: 227-243$. 